\title{
Key proteins as potential effective biomarkers under Intraoperative Radiotherapy (IORT) in tumor bed of Breast Cancer patients
}

\author{
minoo shahani ( $\sim$ minoo.shahani@gmail.com ) \\ cancer research center shahid beheshti medical univercity \\ Jafar Shakeri \\ cancer research center shahid beheshti univercity of medical sciences \\ Ali Tafti \\ cancer research center shahid beheshti univercity of medical sciences \\ Mohammad Esmaeil Akbari \\ cancer research center shahid beheshti univercity of medical sciences
}

\section{Research}

Keywords: Radiotherapy, Breast Conserving Surgery, External Beam RT, Intraoperative Radiation Therapy

Posted Date: March 13th, 2020

DOl: https://doi.org/10.21203/rs.3.rs-17156/v1

License: () (1) This work is licensed under a Creative Commons Attribution 4.0 International License. Read Full License 


\section{Abstract}

Background Radiotherapy (RT) is recommended to all patients undergoing Breast Conserving Surgery (BCS). Two strategies can be applied to irradiation, External Beam RT (EBRT) in addition, Intraoperative Radiation Therapy (IORT). The aim of this study was to introduce a protein biomarker panel related to molecular function under IORT.

Methods Six Breast Cancer (BC) patients as a pilot study were treated by $12 \mathrm{~Gy}$ (Boost dose) and 21 Gy (Radical dose). Samples tissue included Margin before IORT (MB), and Margin 24 hours After IORT (MA24 h). Isobaric Tag for Relative and Absolute Quantitation (iTRAQ) was performed to study proteomic of IORTtreated tumor bed.

Results We classified 110 differentially expressed proteins (DEPs) as a protein biomarker panel by mapping the annotated coding region sequences to the reference canonical pathways in the KEGG database.

Conclusion Our findings indicate that the DEPs may be key proteins in IORT-treated tumor bed and may serve as potential Effective biomarkers under IORT.

\section{Background}

$\mathrm{BC}$ as the fifth leading cause of cancer death is recognized as the most common cancer among women [1]. Considering the advances in early diagnosis and treatment of BC, mortality has reduced by 38\% from 1989 to 2014 [2]. The prevalence of BC was 9795 cases in Iran, and the age-adjusted standardized ratio (ASR) was 28.1 in 100000 people [3]. Akbari et al reported that the five- and ten-year survival rate for BC was estimated to be $81 \%$ and $77 \%$, respectively [4].

RT is recommended to all patients undergoing BCS and some of them after mastectomy. The main objective is to obtain more effective doses of radiation in the appropriate time and site without increasing the prevalence of complications. RT can provide curative treatment in nearly $40 \%$ of patients [5]. In a previous study, long-term outcomes in patients with BCS and RT who were timely diagnosed, were similar to or even better than patients with mastectomy [6].

Two strategies can be applied to deliver irradiation to the cancer site. The first strategy is the use EBRT which is delivered from outside the body to the tumor site via protons, photons, or charged particles [7].

The second strategy is IORT which delivers electron beams (IOERT) and low kv-x-ray (IOXRT) [8]. By applying IORT during BCS, a high single dose is delivered to the site at the highest risk to fight subclinical tumor cell contamination with high precision owing to direct visualization [9]. Tumor bed has been reported as the highest risk of breast tumor recurrence $[10,11]$. As a result, local recurrence can be significantly reduced by using an extra dose to the tumor bed [12]. EBRT can be replaced by accelerating partial breast irradiation, including an IORT session, due to approved several advantages including; lack of gap between surgery and RT, avoidance of long treatment duration, reduced radiation-induced toxicity, tumor bed delineation under direct palpation and visual assessments and sparing non-targeted tissues surrounding the tumor bed [12, 13]. In addition to the delayed time of RT after tumor excision, EBRT has harmful effects, including cardiac attack, appearance of second tumors, or stimulation of tumor cell growth by neo angiogenesis and hypoxia condition [14]. Notably, IORT can also help to save money, time, and $\mathrm{CO}_{2}$ emissions in some patients, inhibiting transportation [15]. Although researchers have shown great interest in a single high-dose clinical approaches for different cancers, limited research has examined the biological basis of IORT [16].

According to specific eligibility criteria, IORT may be delivered either as an anticipated Boost, followed by conventional external RT to guarantee optimal dose delivery, or as an exclusive single radiation dose of Radical, corresponding to the administration of the entire sequence of conventional adjuvant RT [17, 18].

Proteomics analysis can provide a new insight of interactome profile of the efficacy of IORT. To the best of our knowledge, there have been only imperfect efforts to characterize genome or proteome underlying physiological and biological mechanisms of IOeRT-treated tumor beds.

The present study represents ITRAQ based on the samples collected from the tumor bed before and 24 after post irradiation. Our findings highlight the involvement of specific proteins and pathways signatures related to different doses. The analyses of protein functions and signaling pathways of these DEPs reveal a molecular response to IORT, which may shed light to design a model for the individual-centered radiotherapy introduced.

\section{Results}

Identification of differentially expressed proteins classification

We performed iTRAQ quantification after labeling of samples in three replicates (for both doses, and tissue; MB and MA24 h). In total, 1045410 spectrums were generated; also, 31572 peptides and 5860 proteins were identified with 1\% FDR. DEPs for each comparisons of group/treatments analyzed. We found that there were 110 DEPs (37 up regulated, 73 down regulated) as single high dose-independent, which were common in both Boost and Radical doses (Table 2). 


\begin{tabular}{|lll|}
\hline Names & total & elements \\
\hline Common & 110 & A2M SERPINB1 NCF4 CNN1 GCA FMNL1 PTPRC LMNB1 VASP SERPINA3 ALOX5 BASP1 SLC2A3 LBP PTX3 LTF ATP5A1 TLN1 \\
DEPs & & FCGR3A LCP1 C9 MDH1 ANXA5 IDH3A PEA15 CP SUCLA2 S100A9 HSPB1 HRG RPL7A ANXA3 ELANE FGG ASS1 LDHB FGB1 \\
under & BST1 HK3 PRIM2 IDH1 ALDH6A1 DLST C5 CNDP2 ACADVL ITIH3 CALB2 ITGB2 PROS1 TUFM ARHGDIB YWHAG MMP8 PYGB \\
Boost & PADI4 APOH DEFA1 CYBB SPTA1 PLG LYZ 2-sep RPL23A APOA4 C4BPA SUCLG2 HIST1 1H1C BPI PEBP1 ITIH4 ACOT1 C8A MSN \\
and & LGALS1 MYO6 WDR1 YWHAE BCAP31 CFH CNN3 HRG MNDA MPO MYH11 VWF VTN CAMP ALDH7A1 OCIAD1 RP2 AZU1 \\
Radical & HEBP2 HMGB2 ITGAM HIST1H1B HIBCH RNASE3 RETN HADH PRTN3 ITIH2 ANK1 CFB LCN2 SERPINC1 Ctsg FLNA ALDH9A1 C6 \\
& MMP9 \\
\hline
\end{tabular}

Network Analysis Of Deps As Single High Dose-independent

We have analyzed 110 DEPs as single high dose-independent. Cytoscape network analysis represented the most important proteins based on 110 nodes, 350 edges and 6.36 as average node degree and 0.505 as avg. local clustering coefficient (Fig. 1).

According to Fig. 2, we identified a network of 110 DEPs as single high dose-independent. Among all, we found key proteins under Boost and Radical.

Gene ontology enrichment and functional classification $24 \mathrm{~h}$ after IORT

For the better understanding of the biological effects of IORT, we classified 110 DEPs by mapping the annotated coding region sequences to the reference canonical pathways in the KEGG pathway database (Fig. 3).

\section{Discussion}

RT is recommended to all patients undergoing BCS and some of them after mastectomy [22]. Despite the technological advances made in recent decades, RT plans still advise the same total dose per organ tumor, without taking into account the biological differences attributable to the different tumor subtypes [23]. By applying IORT during BCS, a high single dose is delivered to the site at the highest risk to fight subclinical tumor cell contamination with high precision owing to direct visualization [9]. Tumor bed has been reported as the highest risk of breast tumor recurrence [10, 11]. As a result, local recurrence can be significantly reduced by using an extra dose to the tumor bed [12].

Although researchers have shown great interest in a single high-dose clinical approaches for different cancers, limited research has examined the biological and molecular basis of single high-dose effects, especially after IORT [24]. Studies have described that Post-surgery wound fluids (WF) induces an increase in the cell proliferation, migration in addition invasion in BC cell line [25-27]. However, the proteomics analysis of IORT-treated WF has shown an inhibition of cell proliferation and invasion in the BC cell line $[28,29]$. In addition, Cell and molecular traits observed in MCF-7 cells showed a typical senescent phenotype associated with cell proliferation arrest after treatment with IORT [30]. A worthy study was reported that the IORT-induced gene expression profiles and pathways appear to be BC cell-line dependent. The data suggest that some specific gene and pathway signatures seem to be linked to hormone receptor status [31].

In the context of this radiation treatment modality, this study aimed to describe the molecular response, in terms of DEPs and pathways, according to the different doses of IORT. However, this type of investigation would need to be extended to numerous panels of samples; thus, the present work should be considered as a pilot study. Here, we report substantial alterations in proteins expression levels after RT in both dose (Boost and Radical). Our proteomics approach using ITRAQ is a necessary first step for a biological study to describe the common molecular features associated with types of IORT.

According to Table2, we detected 110 overlap DEPs between Boost and Radical doses. The identified overlapping 110 DEPs extracted from IORT $24 \mathrm{~h}$ posttreatment are enriched based on KEGG pathways database by using DAVID.

Functional annotation revealed new insights of IORT in BC patients. Some of the most important pathways such as Complement and coagulation cascades, metabolomics pathways were enriched under IORT (Fig. 3).

We have analyzed 110 DEPs as single high dose-independent. Cytoscape network analysis represented the most important proteins (Fig. 1). All DEPs were classified into 10 protein categories (Fig. 2), in which the most proteins related to RT are PLG, VWF and A2M (Fig. 2). The protein panel obtained corresponds to genes involved in cancer processes whose significantly downregulated after IORT-treated tumor bed [32]. The Plasminogen system produced by PLG (plasminogen) plays a crucial role in physiological in addition, pathological events related to tissue regeneration, wound healing, immune response, angiogenesis, invasion and metastasis. The PLG is significantly downregulated after IORT-treated tumor bed and highly enriched in Complement and coagulation cascades. In addition, Von Willebrand Factor Protein (VWF) is a major platelet ligand that has been widely used, as a biomarker in cancer growth and metastasis and associated inflammation [32], is significantly downregulated at $24 \mathrm{~h}$ post irradiation also highly enriched in Complement and coagulation cascades. As shown in figuere 4, reffre to complement and coagulation cascades kegg pathway data base, enrichment associated with changes in these related key pathway to RT have been illustrated which indicates that two doses of IORT (Fig. 3) is able to reduce cell growth and cell proliferation.

It has been reported in previous stydies that 21-gene recurrence score (RS) were evaluated for prognostic and predictive benefit in IORT patients [33] in addition a value study indicated that key molecular pathways in radiotherapy (RT) are equally enriched by both Boost and Radical doses[34].

Overall, our findings indicate that the DEPs may be key proteins in IORT-treated tumor bed and may serve as potential Effective biomarkers under IORT. 
Eventually, results revealed new insights of IORT in BC management; all of these biological responses in tumor cells may be towards effectiveness of IORT and it shows that although IORT is a local treatment, it can have systemic effects.

\section{Conclusion}

As a conclusion, by using comprehensive techniques such as proteomic, we found the molecular basis of IORT-related changes that have already showed clinical and epidemiological effects in treating BC patients. In addition key biological pathways that induced by IORT indicated that, cellular microenvironment as a main causes of changes in cells through tumor development, can be affected by IORT. Due to the effectiveness of IORT, it may be recommended as a standard method for BC patients.

Ultimately, proteomic study open new insights into personalized RT and this study has discovered another piece of puzzle that identifies the complexities of BC.

\section{Materials And Methods}

Six random selected BC patients entered into our study (Table 1). These eligible patients had neither comorbidity / history of drug nor significant mental health disorder. Informed consent is attached to a separate file. IORT delivered electron beams (LIAC linear accelerators, Sordina IOeRT Technologies S.p.A, Italy), and an Intraoperative accelerator was employed for cell irradiation [19]. Patients were treated with irradiation following two separate strategies, including Boost and Radical dose treatment. The machine dose rate was adjusted to $1 \mathrm{cGy} / \mathrm{MU}$ during the irradiation. Approximately $100 \mathrm{mg}$ of tissue was extracted from tumor bed under Boost and Radical doses; MB, MA24 h.

Table 1

Clinical and pathological data of patients by study groups.

\begin{tabular}{|c|c|c|c|c|c|c|c|c|c|c|c|c|c|c|c|}
\hline & & Patholo & ic data & & & & & & & & & IOeRT dat & & & \\
\hline $\begin{array}{l}\text { Pt } \\
\text { Number }\end{array}$ & Age & $\begin{array}{l}\text { Tumor } \\
\text { history } \\
\text { type }\end{array}$ & $\begin{array}{l}\text { Tumor } \\
\text { size } \\
\text { (cm) }\end{array}$ & $\begin{array}{l}\text { Node } \\
\text { status }\end{array}$ & $\begin{array}{l}\text { Tumor } \\
\text { grade }\end{array}$ & $\begin{array}{l}\text { ER/PR } \\
\text { status }\end{array}$ & $\begin{array}{l}\text { HER-2 } \\
\text { Expression }\end{array}$ & Ki67 & P53 & $\begin{array}{l}\text { Tumor } \\
\text { Necrosis }\end{array}$ & LVI & $\begin{array}{l}\text { Delivered } \\
\text { dose } \\
\text { (Gy) }\end{array}$ & $\begin{array}{l}\text { Irradiation } \\
\text { time } \\
\text { (second) }\end{array}$ & $\begin{array}{l}\text { size } \\
(\mathrm{cm})\end{array}$ & $\begin{array}{l}\text { Fla } \\
\text { dep } \\
\text { (cm }\end{array}$ \\
\hline 1 & 53 & IDC & 4 & No & 3 & $-/-$ & $\mathrm{Neg}$ & $\% 50$ & - & Present & $\begin{array}{l}\text { Not } \\
\text { seen }\end{array}$ & 12 & 63 & $7 / 9$ & 1 \\
\hline 2 & 42 & IDC & 1 & NO & 1 & + & Neg & $30 \%$ & + & Negative & $\begin{array}{l}\text { Not } \\
\text { seen }\end{array}$ & 12 & 55 & $5 / 6$ & 1.6 \\
\hline 3 & 39 & IDC & 2.5 & NO & 2 & $+/+$ & $\mathrm{Neg}$ & $\% 25$ & + & Not seen & $\begin{array}{l}\text { Not } \\
\text { seen }\end{array}$ & 12 & 58 & $6 / 9$ & 1.8 \\
\hline 4 & 63 & ILC & 1.3 & No & 2 & $+/$ & $\mathrm{Neg}$ & \%15 & - & Not seen & $\begin{array}{l}\text { Not } \\
\text { seen }\end{array}$ & 21 & 65 & $5 / 6$ & 2.3 \\
\hline 5 & 48 & IDC & 2 & No & 2 & $+/+$ & $\mathrm{Neg}$ & $\% 30$ & + & Not seen & $\begin{array}{l}\text { Not } \\
\text { seen }\end{array}$ & 21 & 78 & $7 / 9$ & 2.2 \\
\hline 6 & 55 & IDC & 3 & No & 2 & $+/+$ & $\mathrm{Neg}$ & $\% 30$ & + & Not seen & $\begin{array}{l}\text { Not } \\
\text { seen }\end{array}$ & 21 & 85 & $8 / 9$ & 2.5 \\
\hline
\end{tabular}

a

\section{Protein Extraction}

First total proteins were extracted from samples with the TRIzol reagent used as supplied by Invitrogen Life Technologies. Then Proteins of more than $200 \mathrm{ug}$ qualified likewise were labeled to be used for iTRAQ.

Proteomics Assays

Peptide Labeling

The ITRAQ labeling reagents were recovered to ambient temperature, and then transferred into and combined with proper samples. Peptide labeling was performed by iTRAQ Reagent 8-plex Kit according to the manufacturer's protocol. The labeled peptides with different reagents were combined and desalted.

Peptide 1st Dimensional Fractionation

The peptides were reconstituted with buffer $\mathrm{A}\left(5 \% \mathrm{ACN}, 95 \% \mathrm{H}_{2} \mathrm{O}\right.$, adjusted pH to 9.8 with ammonia) and separated by a Shimadzu LC-20AB HPLC system coupled with a high pH RP column (5- $\mu \mathrm{m}$ particles, Phenomenex). The peptides were separated at a flow rate of $1 \mathrm{ml} / \mathrm{min}$ with a $60 \mathrm{~min}$ gradient: $5 \%$ buffer $\mathrm{B}$ ( $5 \% \mathrm{H}_{2} \mathrm{O}, 95 \% \mathrm{ACN}$, adjusted $\mathrm{pH}$ to 9.8 with ammonia) for $10 \mathrm{~min}, 5-35 \%$ buffer B for $40 \mathrm{~min}, 35-95 \%$ buffer B for $1 \mathrm{~min}$, and $95 \%$ buffer B for 3 min. The gradient was then decreased to $5 \%$ B within 1 min before re-equilibrating with $5 \%$ buffer $B$ for 5 min. Elution was monitored by measuring absorbance at $214 \mathrm{~nm}$ and the eluted peptides were pooled as 20 fractions in a concatenation mode and vacuum dried.

Peptide 2nd Dimensional Fractionation 
Each fraction was resuspended in buffer A ( $2 \%$ ACN and 0.1\% FA in water) and loaded onto a C18 trap column using an LC-20AD nano-HPLC instrument (Shimadzu, Kyoto, Japan) by the Autosampler. Then, the peptides were eluted from the trap column and separated by an analytical C18 column (inner diameter $75 \mu \mathrm{m} \cdot 20 \mathrm{~cm}, 3 \mu \mathrm{m})$ packed in-house. The gradient was run at $300 \mathrm{~nL} / \mathrm{min}$ starting from 8 to $35 \%$ of buffer $\mathrm{B}\left(2 \% \mathrm{H} \mathrm{H}_{2} \mathrm{O}\right.$ and $0.1 \% \mathrm{FA}$ in $\left.\mathrm{ACN}\right)$ for 35 minutes, increasing to $60 \%$ for 5 minutes, then maintaining at $80 \%$ B for 5 minutes, and finally returning to $5 \%$ in 0.1 min and keeping for 10 min.

Mass Spectrometer Detection

Data acquisition was performed with a TripleTOF 5600 System (SCIEX, Framingham, MA, USA) equipped with a Nanospray III source (SCIEX, Framingham, MA, USA), a pulled quartz tip as the emitter (New Objectives, Woburn, MA) and controlled with software Analyst 1.6 (AB SCIEX, Concord, ON). Data was acquired with the following MS conditions: ion spray voltage of 2,300 V, curtain gas of 30 , nebulizer gas of 15 , and interface heater temperature of $150{ }^{\circ} \mathrm{C}$. High sensitivity mode was used for the whole data acquisition. The mass ranges for MS1 were from 350 to 1500 Da. Based on the intensity in MS1 survey, as many as 30 product ion scans were collected if exceeding a threshold of 120 counts per second (counts/s) and with charge-state $2+$ to $5+$, dynamic exclusion was set for $1 / 2$ of the peak width (12 s). For iTRAQ data acquisition, the collision energy was adjusted to all precursor ions for collision-induced dissociation and the Q2 transmission window for 100 Da was $100 \%$.

Protein identification and quantification.

The raw MS/MS data were converted into MGF format by ProteoWizard tool msConvert, and the exported MGF files were searched using Mascot version 2.3.02 (Matrix Science, London, UK). In this project against the human Uniprot database. To reduce the probability of false peptide identification, only those peptides with significant scores $(\geq 20)$ with $99 \%$ confidence were counted as identified. The IQuant software was used to quantitatively analyze the labeled peptides with isobaric tags[20]. It integrates Mascot Percolator, a well performing machine learning method for re-scoring database search results, to provide reliable significance measures. In order to assess the confidence of peptides, the PSMs were pre-filtered at a PSM-level FDR of 1\%. Then, based on the "simple principle" (The parsimony principle), identified peptide sequences were assembled into a set of confident proteins. In order to control the rate of false-positive at the protein level, a protein FDR at 1\%, which is based on Picked protein FDR strategy will also be estimated after protein inference (Protein-level FDR < = 0.01) [21]. The protein quantification process includes the following steps: Protein identification, Tag impurity correction, Data normalization, Missing value imputation, Protein ratio calculation, Statistical analysis, and Results presentation. Proteins with 1.2-fold change and Q-value less than 0.05 were determined as differentially expressed protein. For quantification repeat analysis, we used CV to evaluate the reproducibility. CV is defined as the ratio of the standard deviation (SD) to the mean.

Gene functional enrichment analysis

Gene functional enrichment analysis was applied on DEPs. In this study, we used KEGG pathway database by using DAVID (http://david.abcc.ncifcrf.gov/) for functional enrichment analysis.

\section{Abbreviations}

Intraoperative Radiation Therapy (IORT)

Breast Conserving Surgery (BCS)

Breast Cancer (BC)

Margin before IORT (MB)

Margin 24 hours After IORT (MA24 h)

Isobaric Tag for Relative and Absolute Quantitation (iTRAQ)

Differentially expressed proteins (DEPs)

\section{Declarations}

\section{Acknowledgements}

The authors thank Dr. Kui Wu; Cancer Institute, BGI-Research, China National GeneBank (CNGB) for Collaborate for great comments on this manuscript.

\section{Funding}

This research did not receive any specific grant from funding agencies in the public, commercial, or not-for-profit sectors.

\section{Availability of supporting data}

Further information and data sets are available from the corresponding authors on reasonable request.

\section{Authors' contributions}

Conception and design: Mohammad Esmaeil Akbari, Minoo Shahani, Jafar Shakeri 
Author responsible for figs and statistical analyses: Minoo Shahani, Ali Tafti

Development of methodology: Minoo Shahani, Jafar Shakeri

Acquisition of data provided: Mohammad Esmaeil Akbari

Sampling and extraction: Minoo Shahani, Jafar Shakeri

Analysis and interpretation of data (e.g., statistical analysis, biostatistics, computational analysis): Ali Tafti, Minoo Shahani, Jafar Shakeri

Writing, review, and/or revision of the manuscript: Jafar Shakeri, Minoo Shahani, Ali Tafti

\section{Ethical Approval and Consent to participate}

The study was approved by the ethics committees of Shahid Beheshti university of medical sciences (Approval ID:IR.SBMU.RETECH.REC.1397.561) .

\section{Consent for publication}

Patient treated at the cancer research and hospital center of Shahid Beheshti University of medical sciences consented in writing for the use of their anonymous data for research.

\section{Competing interests}

The authors declare that they have no competing interest.

\section{Author's details}

Minoo Shahani ${ }^{1}{ }^{2+}$; Jafar Shakeri ${ }^{1}$; Ali Tafti ${ }^{1}$; Mohammad Esmaeil Akbari ${ }^{1 *}$

- Cancer Research Center, Shahid Beheshti University of Medical Sciences, Tehran, Iran.

- Department of Genetics, Islamic Azad University, Tehran Medical Sciences Branch, Tehran, Iran.

- shahani@gmail.com

- Shakerij12@gmail.com

- tafti1375@gmail.com

- profmeakbari@gmail.com

\section{References}

1. Movahedi M, Haghighat S, Khayamzadeh M, Moradi A, Ghanbari-Motlagh A, Mirzaei H, et al. Survival rate of breast cancer based on geographical variation in iran, a national study. Iran Red Crescent Med J. 2012;14(12):798-804.

2. Siegel RL, Miller KD, Jemal A. Cancer Statistics, 2017. CA Cancer J Clin. 2017;67(1):7-30.

3. Mohebbi E, Nahvijou A, Hadji M, Rashidian H, Seyyedsalehi MS, Nemati S, et al. Iran Cancer Statistics in 2012 and projection of cancer incidence by 2035 Basic \& Clinical Cancer Research. 2018;9(3).

4. Akbari ME, Khayamzadeh M, Khoshnevis S, Nafisi N, Akbari A. Five and ten years survival in breast cancer patients mastectomies vs. breast conserving surgeries personal experience. Iranian Journal of Cancer Prevention. 2008;1(2):53-6.

5. Baskar R, Lee KA, Yeo R, Yeoh KW. Cancer and radiation therapy: current advances and future directions. Int J Med Sci. 2012;9(3):193-9.

6. Onitilo AA, Engel JM, Stankowski RV, Doi SA. Survival Comparisons for Breast Conserving Surgery and Mastectomy Revisited: Community Experience and the Role of Radiation Therapy. Clin Med Res. 2015;13(2):65-73.

7. Cuaron JJ, MacDonald SM, Cahlon O. Novel applications of proton therapy in breast carcinoma. Chin Clin Oncol. 2016;5(4):52.

8. Silverstein MJ, Fastner G, Maluta S, Reitsamer R, Goer DA, Vicini F, et al. Intraoperative radiation therapy: a critical analysis of the ELIOT and TARGIT trials. Part 2-TARGIT. Ann Surg Oncol. 2014;21(12):3793-9.

9. Williams NR, Pigott KH, Brew-Graves C, Keshtgar MR. Intraoperative radiotherapy for breast cancer. Gland Surg. 2014;3(2):109-19.

10. Miyamoto DT, Harris JR. Molecular predictors of local tumor control in early-stage breast cancer. Semin Radiat Oncol. 2011;21(1):35-42.

11. Yoshida $T$, Takei $H$, Kurosumi M, Ninomiya J, Ishikawa $Y$, Hayashi $Y$, et al. True recurrences and new primary tumors have different clinical features in invasive breast cancer patients with ipsilateral breast tumor relapse after breast-conserving treatment. Breast J. 2010;16(2):127-33.

12. Barros AC, Hanna SA, Carvalho HA, Martella E, Andrade FE, Piato JR, et al. Intraoperative full-dose of partial breast irradiation with electrons delivered by standard linear accelerators for early breast cancer. Int J Breast Cancer. 2014;2014:568136.

13. Sedlmayer F, Reitsamer R, Fussl C, Ziegler I, Zehentmayr F, Deutschmann H, et al. Boost IORT in Breast Cancer: Body of Evidence. Int J Breast Cancer. 2014;2014:472516.

14. Brown LC, Mutter RW, Halyard MY. Benefits, risks, and safety of external beam radiation therapy for breast cancer. Int J Womens Health. $2015 ; 7: 449-58$.

15. Coombs NJ, Coombs JM, Vaidya UJ, Singer J, Bulsara M, Tobias JS, et al. Environmental and social benefits of the targeted intraoperative radiotherapy for breast cancer: data from UK TARGIT-A trial centres and two UK NHS hospitals offering TARGIT IORT. BMJ Open. 2016;6(5):e010703.

Page 6/10 
16. Bravata V, Minafra L, Russo G, Forte GI, Cammarata FP, Ripamonti M, et al. High-dose lonizing Radiation Regulates Gene Expression Changes in the MCF7 Breast Cancer Cell Line. Anticancer Res. 2015;35(5):2577-91.

17. Sedlmayer, F.; Reitsamer, R.; Wenz, F.; Sperk, E.; Fussl, C.; Kaiser, J.; Ziegler, I.; Zehentmayr, F.;Deutschmann, H.; Kopp, P.; et al. Intraoperative radiotherapy (IORT) as boost in breast cancer. Radiat. Oncol. 2017, 12, 23. [CrossRef] [PubMed]

18. Harris, E.E.R.; Small, W.J.R. Intraoperative Radiotherapy for Breast Cancer. Front. Oncol. 2017, 7, 317.[CrossRef] [PubMed]

19. Baghani HR, Aghamiri SM, Mahdavi SR, Akbari ME, Mirzaei HR. Comparing the dosimetric characteristics of the electron beam from dedicated intraoperative and conventional radiotherapy accelerators. J Appl Clin Med Phys. 2015;16(2):5017.

20. Wen B, Zhou R, Feng Q, Wang Q, Wang J, Liu S. IQuant: an automated pipeline for quantitative proteomics based upon isobaric tags. Proteomics. 2014;14(20):2280-5.

21. Savitski MM, Wilhelm M, Hahne H, Kuster B, Bantscheff M. A scalable approach for protein false discovery rate estimation in large proteomic data sets. Molecular \& Cellular Proteomics. 2015;14(9):2394-404.

22. Minafra L, Bravata V, Russo G, Forte GI, Cammarata FP, Ripamonti M, et al. Gene Expression Profiling of MCF10A Breast Epithelial Cells Exposed to IOERT. Anticancer Res. 2015;35(6):3223-34.

23. Forte, G.I.; Minafra, L.; Bravatà, V.; Cammarata, F.P.; Lamia, D.; Pisciotta, P.; Cirrone, G.A.P.; Cuttone, G.;Gilardi, M.C.; Russo, G. Radiogenomics: The utility in patient selection. Transl. Cancer Res. 2017, 6 (Suppl.S5), S852-S874. [CrossRef].

24. Paulsen, G.H.U.; Strickert, T.; Marthinsen, A.B.L.; Lundgren, S. Changes in radiation sensitivity and steroid receptor content introduced by hormonal agents and ionizing radiation in breast cancer cells in vitro. Acta Oncol. 1996, 35, 1011-1019. [CrossRef] [PubMed].

25. Segatto, I.; Berton, S.; Sonego, M.; Massarut, S.; Perin, T.; Piccoli, E.; Colombatti, A.; Vecchione, A.; Baldassarre, G.; Belletti, B., Surgery-induced wound response promotes stem-like and tumor-initiating features of breast cancer cells, via STAT3 signaling. Oncotarget 2014, 5, (15), 6267.

26. Valeta-Magara, A.; Hatami, R.; Axelrod, D.; Roses, D. F.; Guth, A.; Formenti, S. C.; Schneider, R. J., Pro-oncogenic cytokines and growth factors are differentially expressed in the post-surgical wound fluid from malignant compared to benign breast lesions. SpringerPlus $2015,4,(1), 483$.

27. Hanahan, D.; Coussens, L. M., Accessories to the crime: functions of cells recruited to the tumor microenvironment. Cancer cell 2012, $21,(3), 309-322$.

28. Belletti, B.; Vaidya, J. S.; D'Andrea, S.; Entschladen, F.; Roncadin, M.; Lovat, F.; Berton, S.; Perin, T.; Candiani, E.; Reccanello, S., Targeted intraoperative radiotherapy impairs the stimulation of breast cancer cell proliferation and invasion caused by surgical wounding. Clinical Cancer Research 2008, 14, (5), 1325-1332.

29. Zaleska, K.; Suchorska, W. M.; Przybyła, A.; Murawa, D., Effect of surgical wound fluids after intraoperative electron radiotherapy on the cancer stem cell phenotype in a panel of human breast cancer cell lines. Oncology letters 2016, 12, (5), 3707-3714.

30. Bravata, V.; Minafra, L.; Russo, G.; Forte, G. I.; Cammarata, F. P.; Ripamonti, M.; Casarino, C.; Augello, G.; Costantini, F.; Barbieri, G., High-dose ionizing radiation regulates gene expression changes in the MCF7 breast cancer cell line. Anticancer research 2015, 35, (5), $2577-2591$.

31. Bravatà, V; Cava, C.; Minafra, L; Cammarata, F.; Russo, G; Gilardi, M; Castiglioni, l; Forte, G., Radiation-induced gene expression changes in high and low grade breast cancer cell types. International journal of molecular sciences 2018, 19 (4).

32. Luo T, Chen X, Zeng S, Guan B, Hu B, Meng Y, Liu F, Wong T, Lu Y, Yun C, Hocher B, Yin L. Bioinformatic identification of key genes and analysis of prognostic values in clear cell renal cell carcinoma. Oncol Lett. 2018;16(2).

33. Barbara S. SchwartzbergaDaniel T and et all...Application of 21-gene recurrence score results and ASTRO suitability criteria in breast cancer patients treated with intraoperative radiation therapy (IORT). The American Journal of Surgery. 2018; 216, (4).

34. Shahani M, Shakeri J, Akbari M,E and et all...Transcriptomic and proteomic approaches reveal biological basis of intraoperative radiotherapy-treated tumor bed modification in breast cancer patients: A pilot study. Journal of Proteomics. 2020; 212, (10).

\section{Figures}




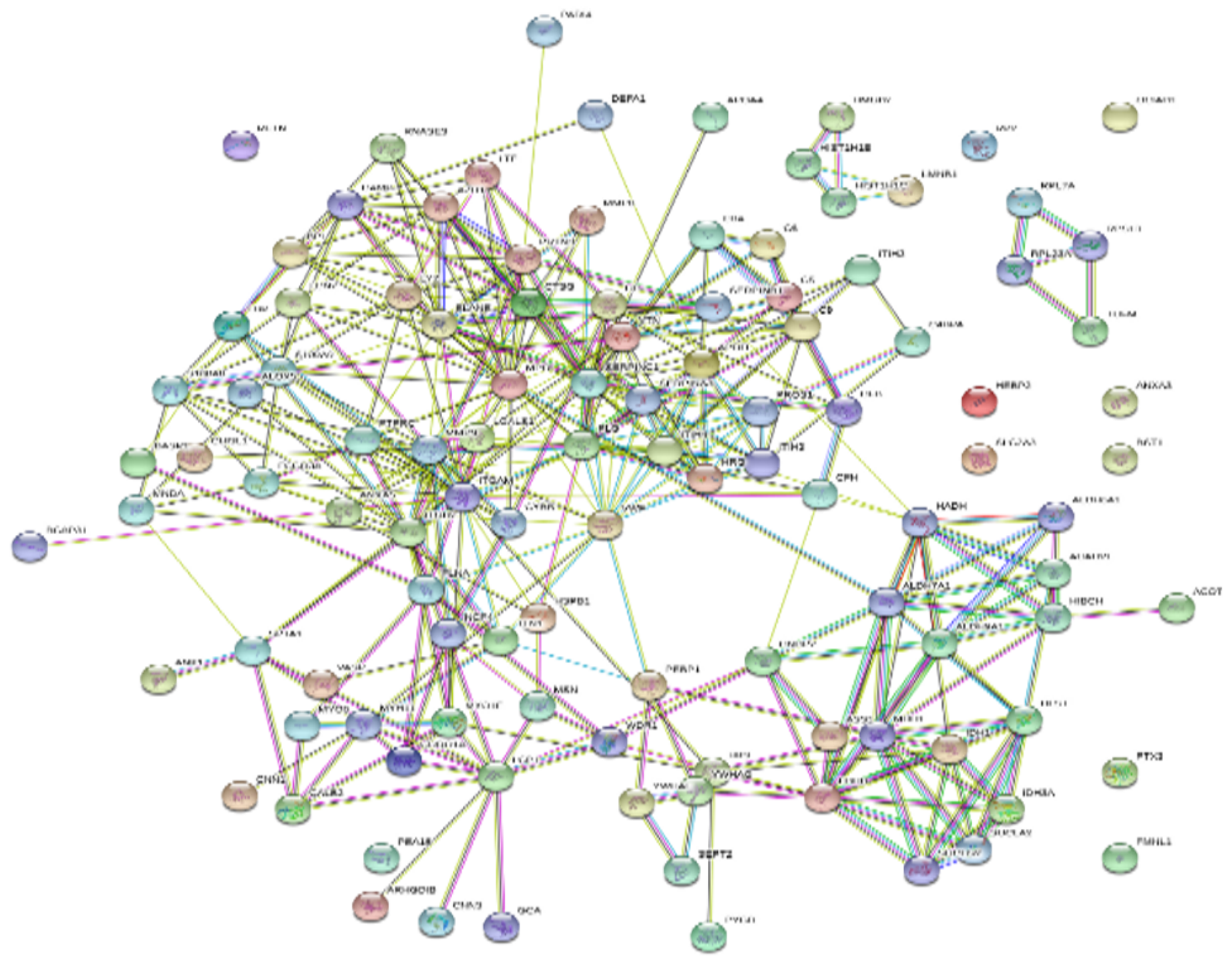

Figure 1

Cytoscape network analysis based on degree by Cytoscape 


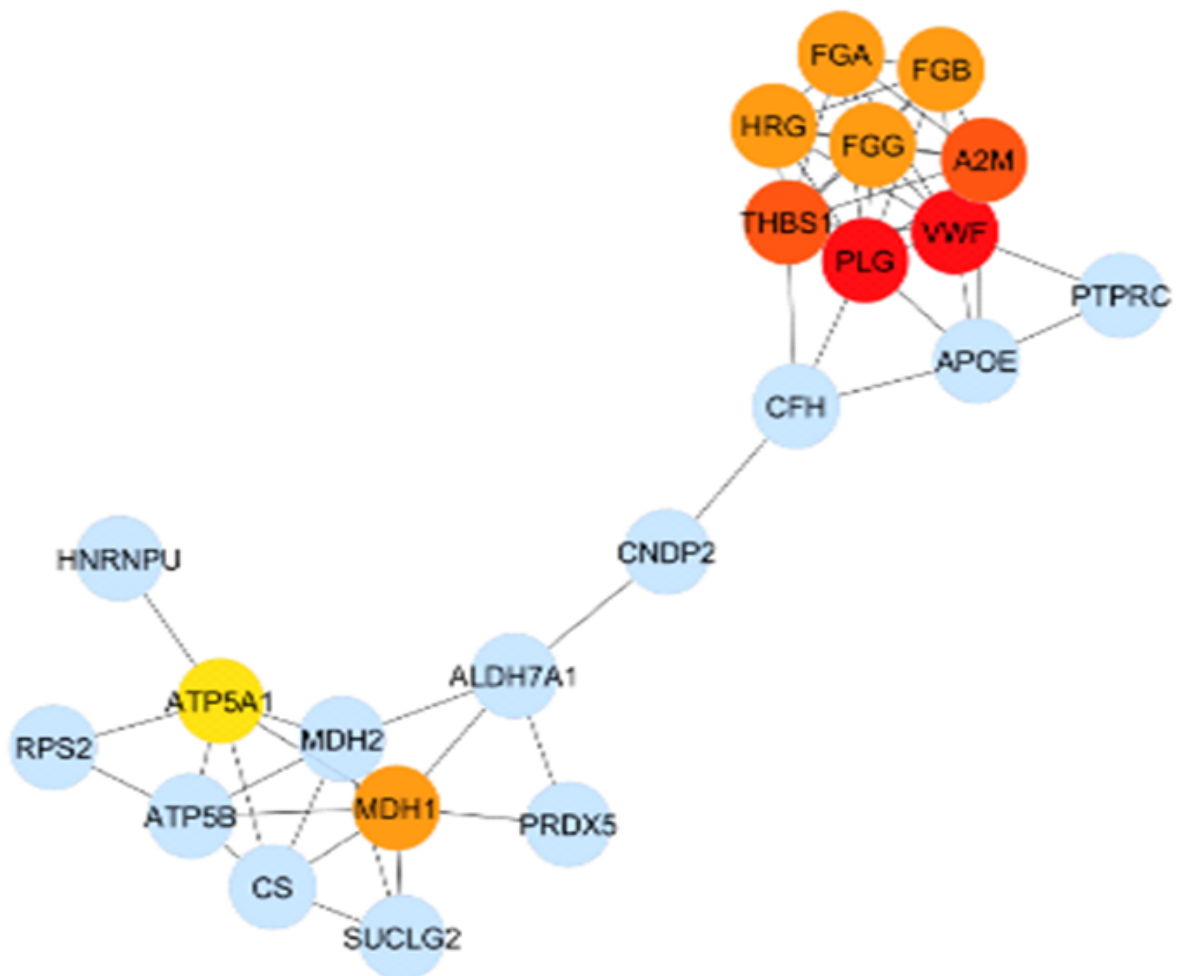

Figure 2

The deregulated densest protein-protein network (blue nodes: proteins, red nodes: proteins involved in crucial pathways) in 110 DEPs

Complement and coagulation cascades_Homo sapiens_hsa04610

Metabolic pathways_Homo sapiens_hsa01100

Citrate cycle (TCA cycle)_Homo sapiens_hsa00020

Carbon metabolism_Homo sapiens_hsa01200

Pyruvate metabolism_Homo sapiens_hsa00620

Platelet activation_Homo sapiens_hsa04611

Cysteine and methionine metabolism_Homo sapiens_hs a00270

Glyoxylate and dicarboxylate metabolism_Homo sapiens_hs a00630

Staphylococcus aureus infection_Homo sapiens_hsa05150

Biosynthesis of amino acids_Homo sapiens_hsa01230

Figure 3

KEGG pathways on 110 DEPs $24 \mathrm{~h}$ after IORT 


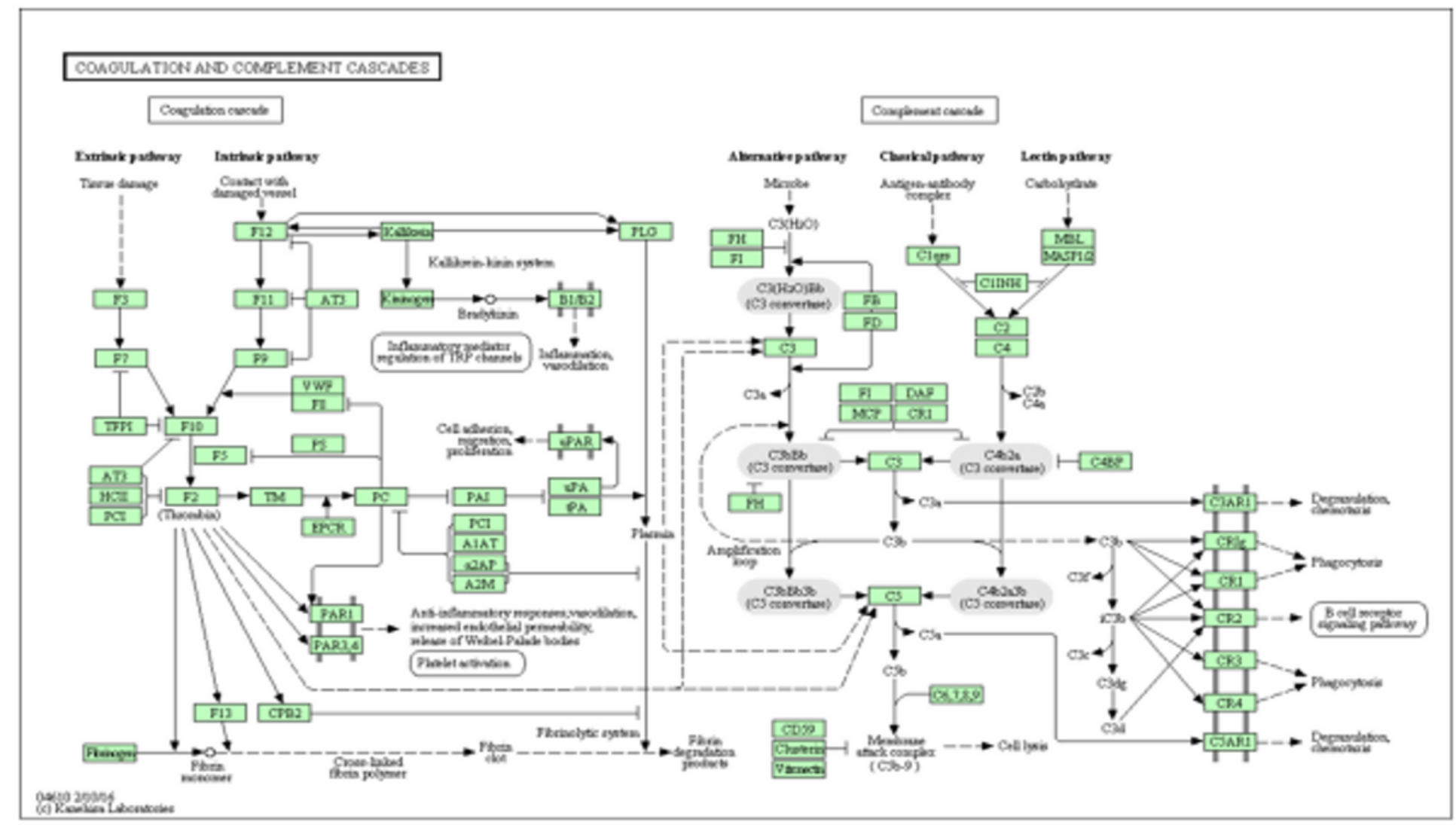

Figure 4

Reffre to complement and coagulation cascades kegg pathway 